\title{
Physician and Patient Perceptions of Physical Touch in Primary Care Consultations in Lebanon: A Qualitative Study
}

\author{
Nancy Zeaiter ${ }^{19}$, Maher A. Ghandour ${ }^{19}$, Maryse Hayek ${ }^{1,2,3}$, Imadeddine Farfour', Ali Dabbous ${ }^{5}$, \\ Mhamad Ali Hajj Hassan ${ }^{6}$, Houssein Haidar Ahmad', Hussein Al Hussein ${ }^{8}$, Fadi Abou-Mrad ${ }^{1,9}$ \\ ${ }^{1}$ Division of Medical Ethics, Faculty of Medical Sciences, Lebanese University, Beirut, Lebanon \\ ${ }^{2}$ Faculty of Medical Sciences, Lebanese University, Beirut, Lebanon \\ ${ }^{3}$ Clinical Psychology Unit, Department of Neurosciences, Saint Charles Hospital, Beirut, Lebanon \\ ${ }^{4}$ Department of General Surgery, Lebanese University Hospital Geitaoui, Beirut, Lebanon \\ ${ }^{5}$ Department of General Surgery, Sahel General Hospital, Beirut, Lebanon \\ ${ }^{6}$ Department of General Surgery, Al Zahraa Hospital University Medical center, Beirut, Lebanon \\ ${ }^{7}$ Department of General Surgery, Saint George Hospital, Hadath, Lebanon \\ ${ }^{8}$ Department of Internal Medicine, Lebanese University Hospital Geitaoui, Beirut, Lebanon \\ ${ }^{9}$ Division of Neurology, Faculty of Medical Sciences, Lebanese University, Beirut, Lebanon \\ "Authors contributed equally to this work
}

Corresponding Author: Nancy Zeaiter, Beirut, Lebanon, zeaiternancy@gmail.com

Division of Medical Ethics, Faculty of Medical Sciences, Lebanese University, Beirut, Lebanon

Financial support: None

Conflict of Interest: None

\begin{abstract}
Background: Verbal and non-verbal communications are an inherent component of physician-patient interactions. The psychological and physiological benefits of non-verbal communication such as gestures, expressions, eye contact, and particularly physical touch in healthcare have been previously explored by the scientific community, albeit insufficiently in the primary care context.
\end{abstract}

Objective: This study aims to address this gap by investigating physician and patient perceptions of expressive touch and its effect on patient satisfaction in primary care consultations in Lebanon.

Methods: We recruited 12 physicians and 13 patients and subjected them to audiotaped semi-structured interviews. We selected the patients from three hospitals, while physician responders were from the Faculty of Medical Sciences of the Lebanese University. We translated the survey instrument into Arabic and validated it using back translation sustained by a pilot study. We performed constant comparative qualitative analysis for obtained relevant data.

Results: Patient satisfaction and trust were associated with good verbal and non-verbal communication. Patient and physician responders recognized the benefit of empathy in building long-term relationships. Social and non-intimate expressive touches were positively perceived by patients, although within ethical and religious boundaries. Male physicians expressed clear apprehension for the use of touch, especially 
towards female patients, due to religious considerations. On the other hand, touch from female physicians was reportedly accepted by patients of both genders, while touch from their male counterparts was associated with more uneasiness.

Discussion and Conclusions: Religious concerns are prevalent among Lebanese physicians and patients alike. However, the use of reassuring physical touch is still a cornerstone of the patient-physician relationship in Lebanon, albeit with some limitations. The potential therapeutic effect of verbal and non-verbal communication is evident and warrants further investigation. Communication training efforts should emphasize the importance of religiously and ethically appropriate expressive touch in healthcare. This would serve to promote positive physician and patient perceptions of this practice and improve clinical communication and expressiveness.

Keywords: Doctor-patient relationship; Nonverbal communication; Patient satisfaction; Primary care; Qualitative research; Physical Touch; Religion Boundaries; Ethical Boundaries; Doctor-Patient Communication

\section{Introduction}

The physician-patient interaction, which includes both verbal and non-verbal communication, remains debatable in the medical field. Satisfactory care requires physician compassion and empathy, albeit without transgressing ethical and professional boundaries. Investigations of the constituents of physician-patient relationships showed that communication characteristics, such as clinician listening and warmth significantly improve patient satisfaction [1]. Moreover, physician friendliness, patience, and accessibility promoted trust and prevented psychological challenges faced by patients upon initial presentation to a healthcare provider [2].

Upon closer examination, a significant gap in medical communication is discerned. Patient dissatisfaction with medical consultations is found to be noteworthy, with predominant emerging issues cited as insufficient provided information and inadequate communication time [3]. Defining appropriate communication strategies in healthcare is therefore critical and depends on both, physician- and patient-reported perception of empathy and communication skills, which can be significantly different between them $[4,5]$.

Touch is an inherent element in physician-patient interactions that is widely accepted, and even expected by patients, and carries psychological as well as clinically relevant outcomes [6]. Lack of nonverbal physician communication through touch incurs dissatisfaction and unhappiness, potentially due to the absence of touch-induced feelings of security $[7,8]$. Moreover, tactile-oriented care ensures the short- and long-term improvement of physiological symptoms experienced by patients, including pain [9].

However, culture-, race- and religion-dependent variations in the impact of non-verbal communication, such as eye contact and touch, exist [10]. As such, physical touching could lead to aggression in the healthcare setting [11], in addition to concerns of sexual harassment [12] and intimacy violations [13]. Despite this, research on the use and consequence of both procedural and expressive touch remains scarce [6].

This study aims to investigate physician and patient perceptions of expressive physical touch in primary care consultations in the context of a culturally and religiously diverse country: Lebanon.

\section{Methods}

\section{Study design}

We conducted semi-structured interviews with patients and doctors following a questionnaire adopted from Cocksedge et al. (2013) [6]. The questionnaire is a culturally appropriate and valid instrument allowing the easy evaluation of the physician-patient relationship (Supplementary Appendix). The questions were sufficiently narrow that it was easy to code the answers based on specific types of answers, thus allowing effective data coding [14]. We obtained permission to use and securely print the survey instrument from the British Journal of General Practice and the corresponding author. We ensured translation accuracy by the translation of the questionnaire from English to Arabic and then back into English according to basic guidelines in this field. The 
Arabic questionnaire version improved accessibility to non-English speakers. The conservation of the original survey items meaning was tested on a small sample of respondents before the initiation of the study and was found to be both valid and reliable for the Lebanese population.

\section{Study population and recruitment}

We randomly selected physicians in the Lebanese University through a list provided by the university administration. We contacted a total of 25 physicians by telephone, 12 of whom verbally consented to participate in audiotaped interviews. After obtaining the permission of three hospitals affiliated to the Lebanese University and representative of the Lebanese population, namely the Lebanese University Hospital Geitaoui, Rafic Hariri University Hospital, and Sahel General Hospital, we randomly selected 25 patients from the three culturally-diverse hospitals to include patients of different ethnic and cultural backgrounds. 13 hospitalized non-dependent patients consented orally to participate in this study. We did not establish any relationship with the physicians or patients before conducting the interviews, and we informed all physicians and patients about the aim of the study. The first and second authors jointly conducted the interviews with the physicians in their clinics, and with the patients in the hospitals.

\section{Data collection and analysis}

We collected data in June and July of 2019. The doctors' interview subject guide included inquiries investigating doctors' perspectives on overseeing individuals with long haul conditions, and the utilization of touch in consultations. Patient interview subjects incorporated their comprehension and encounters of a continuous doctor-patient relationship, concentrating fundamentally on the utilization of non-verbal correspondence and touch with regards to therapeutic collaborations [6].

Audio taped interviews were 10 minutes on average and we transcribed them to frame the information that is liable to examination, then we erased them. Recruitment proceeded until data saturation was reached. We coded the transcriptions and analyzed them according to the constant comparative method of Strauss and Corbin [15]. Physician and patient demographics and practice factors were taken into consideration in the analysis of the data, to account for any possible variations in primary care perceptions.

\section{Results}

The demographics of the 12 physicians and 13 patients that we interviewed are presented in Tables 1 and 2, respectively. Data analysis themes were adopted from the study of Cocksedge et al. (2013) [6] and consisted of (1) communication (verbal and non-verbal) in ongoing doctor-patient relationships, (2) communicating using touch, and (3) limits to the use of touch.

\section{(1) Communication in ongoing doctor-patient relationships}

Physicians generally emphasized the importance of establishing a long-term relationship with their patients, and some considered it a doctor's duty. Both patients and doctors reported that good communication in an ongoing doctor-patient relationship not only promotes greater patient confidence in his doctor but also facilitates patient follow-up and diagnosis of emerging medical issues, thus improving treatment outcomes.

\begin{abstract}
"When I see the patient regularly, the patient will know me. He will be more comfortable, and he will trust me more. Knowing his clinical and personal state, it becomes easier for me to discover any emerging medical issues." Physician 10.
\end{abstract}

Patients also stressed the importance of a good physician-patient relationship in gaining knowledge about the medical and personal history of the patient, thus improving the quality of care.

"If the doctor knows the patient, this helps him establish a diagnosis with more ease... If I know him well, I will be more comfortable when I consult him because I will trust him more." Patient 10

According to respondents, both patients and physicians, regular consultations with the same physician and non-verbal communication provided avenues for psychological support, including, but not limited, to sympathy, care, and dedication.

\footnotetext{
"I always go to my family doctor. He is very respectful, and he keeps smiling. He is supportive. I trust him, and I think that psychological wellbeing is more important than physical wellbeing." Patient 2.
} 


\begin{tabular}{|c|c|c|c|c|c|c|c|}
\hline PhRef & Gender & $\begin{array}{c}\text { Years } \\
\text { Qualified }\end{array}$ & $\begin{array}{l}\text { Rural/semi- } \\
\text { rural/urban } \\
\text { practice }\end{array}$ & $\begin{array}{l}\text { Size of patient } \\
\text { list/patient } \\
\text { demographics }\end{array}$ & $\begin{array}{l}\text { Teaching } \\
\text { practice }\end{array}$ & Specialty & Fields of interest \\
\hline 1 & Male & 16 & Urban & 1000/Mixed & Yes & Orthopedics & Spine Surgery \\
\hline 2 & Male & 30 & Urban & 86400/Mixed & Yes & $\begin{array}{l}\text { Geriatrics and } \\
\text { Endocrinology }\end{array}$ & $\begin{array}{l}\text { Acute hospital and } \\
\text { palliative care and } \\
\text { rehabilitation }\end{array}$ \\
\hline 3 & Male & 7 & Rural & 1750/Mixed & Yes & General Surgery & Bariatric \\
\hline 4 & Male & 9 & Rural & 21600/Mixed & No & Urology & Kidney Transplantation \\
\hline 5 & Male & 32 & Urban & 10000/Mixed & Yes & General Surgery & Laparoscopic Surgery \\
\hline 6 & Male & 35 & Urban & $\begin{array}{l}\text { 15000/South } \\
\text { of Lebanon }\end{array}$ & Yes & $\begin{array}{l}\text { Obstetrics and } \\
\text { Gynecology }\end{array}$ & General Gynecology \\
\hline 7 & Male & 31 & Urban & 10000/Mixed & Yes & Gastroenterology & $\begin{array}{c}\text { Motility disorder of Gl } \\
\text { tract }\end{array}$ \\
\hline 8 & Female & 12 & $\begin{array}{l}\text { Semi- } \\
\text { Urban/Rural }\end{array}$ & 158400/Mixed & Yes & Endocrinology & $\begin{array}{l}\text { General endocrinology } \\
\text { for adults and pediatrics }\end{array}$ \\
\hline 9 & Female & 30 & Urban & 40000/Mixed & Yes & $\begin{array}{l}\text { Infectious } \\
\text { Diseases }\end{array}$ & Multidrug resistance \\
\hline 10 & Male & 15 & Urban & 108000/Mixed & No & $\begin{array}{l}\text { Infectious } \\
\text { Diseases }\end{array}$ & $\begin{array}{l}\text { Immunocompromised } \\
\text { patients }\end{array}$ \\
\hline 11 & Male & 23 & Urban & 99600/Mixed & Yes & Psychiatry & Bipolar disease \\
\hline 12 & Female & 7 & Rural & 30000/Mixed & No & $\begin{array}{c}\text { General } \\
\text { Practitioner }\end{array}$ & $\begin{array}{c}\text { Critical care patients on } \\
\text { mechanical ventilation, } \\
\text { sepsis }\end{array}$ \\
\hline
\end{tabular}

Table 1: Demographic and practice characteristics of 12 Lebanese physician respondents providing primary care (June-July 2019). All physicians belonged to the Middle Eastern Lebanese ethnicity. PhRef: Physician Reference.

\section{"Long-term patient follow-up improves significantly with a supportive attitude. Of course, he could be on medication, but the psychological support makes him respond well to treatment." Physician 7.}

Interviewees often cited that good verbal communication from the physician's end as a critical precursor for patient trust and satisfaction with the consultation.

"My relationship with my doctor is good because he explains to me everything about my case. He gives me his time, which is the most important thing. It's very bad if the doctor lets you feel that he is in a hurry." Patient 7.

Patients reported greater comfort, confidence, and trust, and thus, better compliance with physician suggestions/treatments with increasing doctorpatient familiarity.

\begin{abstract}
"Doctors who know their patients well are more caring and take less time to understand their complaints and correlate them with the disease. When I know the doctor more, I trust him more, and I find myself more compliant with his treatment plan and suggestions." Patient 8.
\end{abstract}

Physicians unanimously agreed on the necessity of dealing with patients professionally without showing emotions. Patients, on the other hand, stressed the importance of doctor friendliness. The majority considered emotional exhibitions from doctors to be "humane", kind and sympathetic, while others considered it a weakness and insisted a doctor provide patients with unwavering emotional support.

"I think the doctor who gets upset in front of his patient is weak. The doctor should be strong because the patient takes strength from the doctor." Patient 2 


$\begin{array}{ccccccc}\text { Patient } & \text { Sex } & \text { Age } & \text { Religion } & \text { Location } & \text { Employment status } & \text { Highest Qualification } \\ \mathbf{1} & \text { Female } & 55 & \text { Muslim } & \text { Urban } & \text { Unemployed } & \text { Secondary school } \\ \mathbf{2} & \text { Male } & 46 & \text { Muslim } & \text { Urban } & \text { Employed } & \text { University degree } \\ \mathbf{3} & \text { Male } & 56 & \text { Christian } & \text { Urban } & \text { Employed } & \text { Primary school } \\ \mathbf{4} & \text { Female } & 61 & \text { Muslim } & \text { Urban } & \text { Employed } & \text { University degree } \\ \mathbf{5} & \text { Female } & 51 & \text { Muslim } & \text { Urban } & \text { Employed } & \text { University degree } \\ \mathbf{6} & \text { Female } & 37 & \text { Muslim } & \text { Urban } & \text { Employed } & \text { University degree } \\ \mathbf{7} & \text { Female } & 50 & \text { Muslim } & \text { Urban } & \text { Employed } & \text { University degree } \\ \mathbf{8} & \text { Female } & 60 & \text { Muslim } & \text { Rural } & \text { Unemployed } & \text { No formal schooling } \\ \mathbf{9} & \text { Female } & 27 & \text { Muslim } & \text { Urban } & \text { Unemployed } & \text { University degree } \\ \mathbf{1 0} & \text { Female } & 48 & \text { Muslim } & \text { Urban } & \text { Unemployed } & \text { University degree } \\ \mathbf{1 1} & \text { Female } & 30 & \text { Muslim } & \text { Urban } & \text { Unemployed } & \text { University degree } \\ \mathbf{1 2} & \text { Male } & 35 & \text { Muslim } & \text { Urban } & \text { Employed } & \text { University degree } \\ \mathbf{1 3} & \text { Male } & 50 & \text { Christian } & \text { Urban } & \text { Employed } & \text { University degree }\end{array}$

Table 2: Demographic characteristics of 13 Lebanese patient responders having received primary care (June-July 2019)

"In general, a doctor will become adapted to such situations [death] with time, but the doctor should have a sense of humanity and not lose his kindness at all." Patient 9

\section{(2) Communication using touch}

$91.7 \%$ of physicians (100\% males and $66.66 \%$ females) and all patients reported that touch, principally through handshaking, reflected politeness and respect, as is customary in Lebanese society. It is important to note that while all female patients were in favor of touch, 55.55\% of them expressed this only towards female, and not male, physicians due to religious beliefs

"Shaking hands is a psycho-socio-ethical matter. It's normal in our routine day-to-day life to shake hands with patients." Physician 5.

"I support shaking hands because, in our culture, shaking hands reflects peace between the two parties, which is very important for patient treatment." Patient 13.

Physicians and patients similarly perceived handshakes to put patients at ease and ensure their comfort showing a doctor's trustworthiness kindness, and humaneness. Female physicians in their majority expressed some limitations to the use of handshakes according to their religious beliefs, particularly with male patients.

"If the doctor shakes hands with me, I feel so much happier, and this also gives psychological support." Patient 6.

"Usually, I prefer to shake hands with patients. I think this gives them the feeling of peace and reassurance and lets the patient feel that the doctor is modest and friendly." Physician 10.

Physical touch beyond handshakes was also used by physicians and reported by the majority of patient respondents. The Lebanese greeting custom, embodied by kisses on the cheek and a hug, was occasionally practiced in clinics. Patients accepted non-procedural touches, such as tapping on the back, shoulder, or hand, and considered them friendly, comforting, satisfying, and reassuring gestures. 
"Touching other than the examination is always acceptable if the doctor is sympathizing with you. It is a kind of reassurance." Patient 5.

"When my doctor shakes my hand or kisses my forehead, I feel happy. I feel satisfied with this behavior." Patient 4.

Physicians practiced expressive touch, providing physical support to patients, but reported an equal preference for hands-free patient handling outside the context of physical examinations.

"We should know well the power of a touch, a smile, a kind word, a listening ear, an honest compliment, or the smallest act of caring." Physician 2.

"I don't think I need physical touch. Confidence comes when you are professional, not when using physical touch." Physician 9.

The majority of physicians expressed their acceptance of reciprocated physical touch within the ethical limits of a patient-doctor relationship, despite potential conflicts with their religious beliefs.

"I don't have a problem when patients touch me. I don't refuse them, it is normal." Physician 4.

Patients reported initiating physical contact with their physicians through hugs and kisses, and they generally perceived such acts as an expression of friendliness and gratitude for the services rendered.

"Yes, I hug my doctor, which makes me feel happier and more satisfied. This gives me psychological support." Patient 13.

\section{(3) Limits to the use of touch}

Physicians generally showed a greater predilection for same-sex interactions, owing to religious restrictions. Age, sex, physician's specialty, and patient's emotional status generally affected the practice and the perceived use of extra-procedural physical touch. Expressive touch was principally avoided by male doctors when treating unaccompanied young patients of the opposite sex, especially when veiled. Such patients similarly reported their apprehension of male touch due to religious principles. However, there was a consensus from these patients on the tolerability of male touch intended for comfort or sympathy. Patients of both genders generally expressed a predilection for touch from a female physician, and while the majority of female physicians unconditionally accepted informal sympathetic touch, male physicians' descriptions included same-gender and age-dependent preferences.

"With ladies, we should be sensitive. If the patient is alone and young, or due to religious barriers, I do not exhibit physical touch beyond the physical examination. If she is an elderly patient, it is usually more accepted." Physician 2.

\section{Discussion}

Our data validate the importance of non-verbal and verbal communication in the promotion of patient satisfaction in medical encounters. Physician empathy and friendliness were reported in this study as critical elements of patient perceptions of high-quality of care and satisfaction with the consultation. This is consistent with previous studies correlating perceived physician competence with empathetic nonverbal behavior, such as eye contact [16]. Moreover, physicians who included positive reinforcement and reassurance while communicating with patients were perceived to be patient-centered and empathetic [17]. The enhancement of the therapeutic association between a physician and his patient through the addition of warmth in communication, embodied by active listening and empathetic statements was also demonstrated to ensure clinically significant improvements in treatment outcomes [18]. Leaning forward and social talk ensured higher patient satisfaction with the medical consultation, as opposed to perceived physician distant and patronizing attitude [1].

Physician and patient responders in our study associated healthy communication in a long-term medical interaction with improved treatment outcomes and enhanced diagnostic ability. This was widely reported across the literature, which showed that the patient-clinician relationship significantly influenced both objective and validated subjective healthcare outcomes [19]. Patients valued a continuing patient-doctor relationship and perceived it to provide feelings of coherence, trust as well as confidence in provided care [20]. However, although patients welcomed friendliness, especially if distressed, the medical community remains apprehensive of affective or emotional involvement, as described by physician respondents in our study and that of Cocksedge et al. [6].

Moreover, the present study reflected that patients had more trust, higher confidence, better 
compliance, and improved psychological wellbeing, if they perceived high physician involvement during the consultation, and received sufficient knowledge of their medical history, through both verbal and non-verbal communication. Previous research supported the importance of perceived physician dedication and empathy for the improvement of patient-physician communication. Increased patient perceptions of a clinician's empathy were observed concomitantly with longer consultations [21]. This reflects patients' need for ample time and physician involvement to adequately discuss their problems, which is especially relevant for patients of low socioeconomic backgrounds [22]. Patients felt more satisfied and had a better understanding of their conditions when physicians spent more time at their bedside. This modification of their perception was reportedly due to physicians sitting while interacting with patients during follow-up, as opposed to standing [23]. The latter practice also increased patient perceptions of involved physician listening as well as the accessibility of provided medical explanation [24]. Enhanced communication through the use of non-verbal physician communication thus exhibits a critical influence on patient outcomes and perceptions and could allow the practice of shared decision making. The latter was shown to significantly improve the quality of the physician-patient relationship [25], as well as patient satisfaction with treatment [26].

Consistently with Cocksedge et al., social touch, including handshaking and rarely, kisses on the cheek, was widely accepted and welcomed by both physicians and patients in our study [6]. It was considered to show politeness and respect from the former, while the latter felt happiness, trust, and comfort. Handshaking made patients perceive their physician as kind, humane, and approachable. Patients seem to perceive non-verbal physician communication positively, with a lack of touch associated with unhappiness [7]. This may be due to the comforting effect of touch in medical care when patients are often vulnerable. A study shows that feelings of security may even be induced when anesthetized patients are touched by the attending nurse anesthetist [8]. The perception of nonintimate physical touch as comforting and healing persists in contexts devoid of physical incapacitation, though, with decidedly higher acceptance of touch received from female or familiar physicians [27], and this is consistent with reports from patient responders in our study.
Non-procedural touch carries clinically relevant benefits, in addition to its effect on patient psychological well-being. Integrating touch into patient care through tactile caregiver involvement ensured a significant decrease in all cancer patient symptoms such as pain and depression [28], as well as the improvement of patient well-being up to 6 months after receiving medical care [9].

However, incidents in emergency primary care settings reveal the capacity of physical touch to trigger violent behavior in patients receiving unsolicited, unannounced touch [11]. Touch by male healthcare providers is also often sexualized and associated with concerns of inappropriate behavior [29]. Male nurses report a high risk of accusations of sexual harassment due to the misconstruction of intimate touch undertaken during the care of female patients [12]. This explains the apprehension expressed by male physician responders in our study towards touching female patients, especially those that are veiled or of young age and presenting alone. However, consistently with previous research [6], certain physicians expressed their willingness to reconsider nonprocedural physical touch restrictions for the benefit of the patient, albeit within the ethical boundaries of the medical profession.

While the physical limits of touch reflected in our study were similar to those reported by Cocksedge et al., religious concerns predominately precluded the liberal use of both social and affective touch among our respondents. Cultural and religious variables constitute noteworthy predictors of patient expectations from and satisfaction with physician interactions. Sims et al. have demonstrated cultural variations in patient values of affective states, with some patients such as Asian Americans preferring calm, and not excitementfocused, physicians [30]. On the other hand, choosing an obstetrician and gynecologist in a predominately Islamic Arab socio-religious environment did not depend exclusively on the empathetic behavior and communication proficiency of a healthcare provider, but was also significantly influenced by religious beliefs [31]. That being said, physician gender preferences among Muslim females undergoing a physical examination of intimate regions remain unpredictable and inconsistent, with both samegender [31] and opposite gender [32] predilections reported. 
The situational tolerability of same-gender touch described in our study as well as other research in Arab contexts could be attributed to the appreciation of professionalism and competence by Muslim-Arab patients [31,33], which could eclipse religious concerns. Physician characteristics thus play a notable role in influencing patient preferences and satisfaction, which is affected by gender-related communication skills, and not physician gender [34]. Female physicians are perceived to be more empathetic than their male counterparts [35], which supports the preference of touch from a female physician expressed by patient respondents in our study. Extant evidence thus validates the need for developing patient-centered communication strategies and providing culturally competent health services.

\section{Conclusions}

The present study validates that good verbal and non-verbal physician-patient communication promotes patient satisfaction, trust, psychological as well as physical wellbeing. Patients positively perceived both social and non-intimate expressive touches, while physicians expressed some apprehension for the use of non-procedural touch. Religious concerns are prevalent among Lebanese physicians and patients alike but did not preclude the use of comforting and reassuring physical touch. Further research is required for the validation of these findings, especially considering the relative homogeneity of patient respondents in terms of religion and gender. The practice of therapeutic touch should be promoted in the medical community while accounting for cultural, racial, and religious variations in perceptions of non-verbal communication.

\section{Acknowledgements}

The authors thank all participants for their help. The authors also extend their gratitude to the Lebanese University Hospital Geitaoui, Rafic Hariri University Hospital, and Sahel General Hospital for their valuable cooperation.

\section{References}

1. Little P, White P, Kelly J, Everitt H, Gashi S, Bikker A, Mercer S. Verbal and non-verbal behaviour and patient perception of communication in primary care: an observational study. Br J Gen Pract. 2015 Jun;65(635):e35765. doi: 10.3399/bjgp15X685249. PMID: 26009530; PMCID: PMC4439825. https://doi.org/10.3399/bjgp15X685249
2. Dang BN, Westbrook RA, Njue SM, Giordano TP. Building trust and rapport early in the new doctor-patient relationship: a longitudinal qualitative study. BMC Med Educ. 2017 Feb 2;17(1):32. doi: 10.1186/s12909-017-0868-5. PMID: 28148254; PMCID: PMC5288896. https://doi.org/10.1186/s12909-017-0868-5

3. M., S., M., J., Haveri, S., Nath,A. Gaps in doctor patient communication: A community based study. International Journal Of Community Medicine And Public Health [Internet]. 2017;3(1) Available from: https://ijcmph.com/index.php/ijcmph/article/view/688

4. Bernardo MO, Cecílio-Fernandes D, Costa P, Quince TA, Costa MJ, Carvalho-Filho MA. Physicians' self-assessed empathy levels do not correlate with patients' assessments. PLoS One. 2018 May 31;13(5):e0198488. doi: 10.1371/journal.pone.0198488. PMID: 29852021; PMCID: PMC5979004.

https://doi.org/10.1371/journal.pone.0198488

5. Kenny DA, Veldhuijzen W, Weijden Tv, Leblanc A, Lockyer $J$, Légaré F, Campbell C. Interpersonal perception in the context of doctor-patient relationships: a dyadic analysis of doctor-patient communication. Soc Sci Med. 2010 Mar;70(5):763-8. doi: 10.1016/j.socscimed.2009.10.065. Epub 2009 Dec 11. PMID: 20005618. https://doi.org/10.1016/j.socscimed.2009.10.065

6. Cocksedge S, George B, Renwick S, Chew-Graham CA. Touch in primary care consultations: qualitative investigation of doctors' and patients' perceptions. Br J Gen Pract. 2013 Apr;63(609):e283-90. doi: 10.3399/bjgp13X665251. PMID: 23540485; PMCID: PMC3609476. https://doi.org/10.3399/bjgp13X665251

7. Marcinowicz L, Konstantynowicz J, Godlewski C. Patients' perceptions of GP non-verbal communication: a qualitative study. Br J Gen Pract. 2010 Feb;60(571):83-7. doi: 10.3399/bjgp10X483111. PMID: 20132701; PMCID: PMC2814260. https://doi.org/10.3399/bjgp10X483111

8. Karlsson AC, Ekebergh M, Mauléon AL, Almerud Österberg S. "Is that my leg?" patients' experiences of being awake during regional anesthesia and surgery. J Perianesth Nurs. 2012 Jun;27(3):155-64. doi: 10.1016/j.jopan.2012.02.005. PMID: 22612885. https://doi.org/10.1016/j.jopan.2012.02.005

9. Airosa F, Arman M, Sundberg T, Öhlén G, Falkenberg T. Caring touch as a bodily anchor for patients after sustaining a motor vehicle accident with minor or no physical injuries a mixed methods study. BMC Complement Altern Med. 2016 Mar 22;16:106. doi: 10.1186/s12906-016-1084-2. PMID: $\quad 27004552$; PMCID: PMC4804542. https://doi.org/10.1186/s12906-016-1084-2

10. Lorié Á, Reinero DA, Phillips M, Zhang L, Riess H. Culture and nonverbal expressions of empathy in clinical settings: A systematic review. Patient Educ Couns. 2017 Mar;100(3):411-424. doi: 10.1016/j.pec.2016.09.018. Epub 2016 Sep 25. PMID: 27693082. https://doi.org/10.1016/j.pec.2016.09.018

11. Morken T, Alsaker K, Johansen IH. Emergency primary care personnel's perception of professional-patient 
interaction in aggressive incidents -- a qualitative study. BMC Fam Pract. 2016 May 12;17:54. doi: 10.1186/s12875016-0454-7. PMID: 27175735; PMCID: PMC4865021. https://doi.org/10.1186/s12875-016-0454-7

12. Harding T, North N, Perkins R. Sexualizing men's touch: male nurses and the use of intimate touch in clinical practice. Res Theory Nurs Pract. 2008;22(2):88-102. PMID: 18578219. https://doi.org/10.1891/1541-6577.22.2.88

13. Campbell RJ, Yonge O, Austin W. Intimacy boundaries: between mental health nurses \& psychiatric patients. J Psychosoc Nurs Ment Health Serv. 2005 May;43(5):32-9. doi: 10.3928/02793695-20050501-05. PMID: 15960033. https://doi.org/10.3928/02793695-20050501-05

14. Oppenheim AN. The quantification of questionnaire data. In: Research Design: The Logic of Social Inquiry. 2017. p. 208. https://doi.org/10.4324/9781315128498-17

15. Corbin J, Strauss A. Basics of Qualitative Research (3rd ed.): Techniques and Procedures for Developing Grounded Theory [Internet]. 2455 Teller Road, Thousand Oaks California 91320 United States: SAGE Publications, Inc.; 2008. Available from: http://methods.sagepub.com/book/basics-of-qualitativeresearch. https://doi.org/10.4135/9781452230153

16. Kraft-Todd GT, Reinero DA, Kelley JM, Heberlein AS, Baer L, Riess H. Empathic nonverbal behavior increases ratings of both warmth and competence in a medical context. PLoS One. 2017 May 15;12(5):e0177758. doi: 10.1371/journal.pone.0177758. PMID: 28505180; PMCID: PMC5432110.

https://doi.org/10.1371/journal.pone.0177758

17. Wong HM, Bridges SM, McGrath CP, Yiu CK, Zayts OA, $\mathrm{Au}$ TK. Impact of Prominent Themes in Clinician-Patient Conversations on Caregiver's Perceived Quality of Communication with Paediatric Dental Visits. PLoS One. 2017 Jan 3;12(1):e0169059. doi: 10.1371/journal.pone.0169059. PMID: 28046044; PMCID: PMC5207641.

https://doi.org/10.1371/journal.pone.0169059

18. Fuentes J, Armijo-Olivo S, Funabashi M, Miciak M, Dick B, Warren S, Rashiq S, Magee DJ, Gross DP. Enhanced therapeutic alliance modulates pain intensity and muscle pain sensitivity in patients with chronic low back pain: an experimental controlled study. Phys Ther. 2014 Apr;94(4):477-89. doi: 10.2522/ptj.20130118. Epub 2013 Dec 5. Erratum in: Phys Ther. 2014 May;94(5):740. PMID: 24309616. https://doi.org/10.2522/ptj.20130118

19. Kelley JM, Kraft-Todd G, Schapira L, Kossowsky J, Riess $\mathrm{H}$. The influence of the patient-clinician relationship on healthcare outcomes: a systematic review and metaanalysis of randomized controlled trials. PLoS One. $2014 \mathrm{Apr}$ 9;9(4):e94207. doi: 10.1371/journal.pone.0094207. Erratum in: PLoS One. 2014;9(6):e101191. PMID: 24718585; PMCID: PMC3981763.

https://doi.org/10.1371/journal.pone.0094207

20. von Bültzingslöwen I, Eliasson G, Sarvimäki A, Mattsson $B$, Hjortdahl P. Patients' views on interpersonal continuity in primary care: a sense of security based on four core foundations. Fam Pract. 2006 Apr;23(2):210-9. doi: 10.1093/fampra/cmi103. Epub 2005 Dec 16. PMID: 16361395. https://doi.org/10.1093/fampra/cmi103

21. Montague E, Chen PY, Xu J, Chewning B, Barrett B. Nonverbal Interpersonal Interactions in Clinical Encounters and Patient Perceptions of Empathy. J Particip Med [Internet]. 2013;5(e33). Available from: https://participatorymedicine.org/journal/evidence/2013/08/ 14/nonverbal-interpersonal-interactions-in-clinicalencounters-and-patient-perceptions-of-empathy/

22. Mercer SW, Higgins $M$, Bikker AM, Fitzpatrick B, McConnachie A, Lloyd SM, Little P, Watt GC. General Practitioners' Empathy and Health Outcomes: A Prospective Observational Study of Consultations in Areas of High and Low Deprivation. Ann Fam Med. 2016 Mar;14(2):117-24. doi: 10.1370/afm.1910. PMID: 26951586; PMCID: PMC4781514. https://doi.org/10.1370/afm.1910

23. Swayden KJ, Anderson KK, Connelly LM, Moran JS, McMahon JK, Arnold PM. Effect of sitting vs. standing on perception of provider time at bedside: a pilot study. Patient Educ Couns. 2012 Feb;86(2):166-71. doi: 10.1016/j.pec.2011.05.024. Epub 2011 Jun 30. PMID: 21719234. https://doi.org/10.1016/j.pec.2011.05.024

24. Merel SE, McKinney CM, Ufkes P, Kwan AC, White AA. Sitting at patients' bedsides may improve patients' perceptions of physician communication skills. J Hosp Med. 2016 Dec;11(12):865-868. doi: 10.1002/jhm.2634. Epub 2016 Jul $5 . \quad$ PMID: 27378679. https://doi.org/10.1002/jhm.2634

25. Bieber C, Müller KG, Blumenstiel K, Hochlehnert A, Wilke S, Hartmann M, Eich W. A shared decision-making communication training program for physicians treating fibromyalgia patients: effects of a randomized controlled trial. J Psychosom Res. 2008 Jan;64(1):13-20. doi: 10.1016/j.jpsychores.2007.05.009. PMID: 18157994. https://doi.org/10.1016/j.jpsychores.2007.05.009

26. Ladin K, Lin N, Hahn E, Zhang G, Koch-Weser S, Weiner DE. Engagement in decision-making and patient satisfaction: a qualitative study of older patients' perceptions of dialysis initiation and modality decisions. Nephrol Dial Transplant. 2017 Aug 1;32(8):1394-1401. doi: 10.1093/ndt/gfw307. PMID: 27576590; PMCID: PMC5837335. https://doi.org/10.1093/ndt/gfw307

27. Osmun WE, Brown JB, Stewart M, Graham S. Patients' attitudes to comforting touch in family practice. Can Fam Physician. 2000 Dec;46:2411-6.

28. Collinge W, Kahn J, Walton T, Kozak L, Bauer-Wu S, Fletcher K, Yarnold P, Soltysik R. Touch, Caring, and Cancer: randomized controlled trial of a multimedia caregiver education program. Support Care Cancer. 2013 May;21(5):1405-14. doi: 10.1007/s00520-012-1682-6. Epub 2012 Dec 21. PMID: 23262808; PMCID: PMC3612588. https://doi.org/10.1007/s00520-012-1682-6

29. Evans JA. Cautious caregivers: gender stereotypes and the sexualization of men nurses' touch. J Adv Nurs. 2002 Nov;40(4):441-8. doi: 10.1046/j.1365-2648.2002.02392.x. 
PMID: $\quad$ 12421403. https://doi.org/10.1046/j.13652648.2002.02392.x

30. Sims T, Koopmann-Holm B, Young HR, Jiang D, Fung H, Tsai JL. Asian Americans respond less favorably to excitement (vs. calm)-focused physicians compared to European Americans. Cultur Divers Ethnic Minor Psychol. 2018 Jan;24(1):1-14. doi: 10.1037/cdp0000171. Epub 2017 Jul 17. PMID: 28714709; PMCID: PMC5771974. https://doi.org/10.1037/cdp0000171

31. Rizk DE, El-Zubeir MA, Al-Dhaheri AM, Al-Mansouri FR, Al-Jenaibi HS. Determinants of women's choice of their obstetrician and gynecologist provider in the UAE. Acta Obstet Gynecol Scand. 2005 Jan;84(1):48-53. doi: 10.1111/j.0001-6349.2005.00705.x. PMID: 15603567. https://doi.org/10.1111/j.0001-6349.2005.00705.x

32. McLean M, Al Yahyaei F, Al Mansoori M, Al Ameri M, Al Ahbabi S, Bernsen R. Muslim women's physician preference: beyond obstetrics and gynecology. Health Care Women Int. 2012;33(9):849-76. doi: 10.1080/07399332.2011.645963. PMID: 22891743. https://doi.org/10.1080/07399332.2011.645963

33. Amir H, Tibi Y, Groutz A, Amit A, Azem F. Unpredicted gender preference of obstetricians and gynecologists by Muslim Israeli-Arab women. Patient Educ Couns. 2012 Feb;86(2):259-63. doi: 10.1016/j.pec.2011.05.016. Epub 2011 Jun 16.21680130. https://doi.org/10.1016/j.pec.2011.05.016

34. Christen RN, Alder J, Bitzer J. Gender differences in physicians' communicative skills and their influence on patient satisfaction in gynaecological outpatient consultations. Soc Sci Med. 2008 Apr;66(7):1474-83. doi: 10.1016/j.socscimed.2007.12.011. Epub 2008 Jan 28. PMID: 18222586. https://doi.org/10.1016/j.socscimed.2007.12.011

35. Nicolai J, Demmel R. The impact of gender stereotypes on the evaluation of general practitioners' communication skills: an experimental study using transcripts of physicianpatient encounters. Patient Educ Couns. 2007 Dec;69(13):200-5. doi: 10.1016/j.pec.2007.08.013. Epub 2007 Oct 17. PMID: 17942269. https://doi.org/10.1016/j.pec.2007.08.013 